\title{
Masonería y cosmopolitismo en el Uruguay del siglo XIX
}

Freemasonry and Cosmopolitanism in Nineteenth Century Uruguay

\author{
Efraín Cano Roa \\ Universidad de Montevideo, Uruguay \\ efraincano42@gmail.com
}

Recepción: 27 de septiembre de 2017/Aceptación: 18 de noviembre de 2017

doi: https://doi.org/10.15517/rehmlac.v9i2.31578

Palabras clave

Masonería; Uruguay; cosmopolitismo; nacionalidades; ocupaciones.

Keywords

Freemasonry; Uruguay; Cosmopolitanism; nationalities; Occupations.

Resumen

Esta investigación inédita sobre las relaciones socio-ocupacionales y orígenes de los masones uruguayos del siglo XIX tiene como objetivo dar a conocer las bases sociales de la masonería nacional. Las principales fuentes documentales utilizadas fueron extraídas de los principales archivos del país junto con documentos internos de la masonería. La estructura del trabajo gira en torno al estudio de tres periodos, analizando la nacionalidad, ocupaciones, distribución geográfica de logias y predominio de ciertos grupos en los talleres masónicos con el fin de intentar responder la siguiente pregunta ¿quiénes integraban realmente la masonería en el siglo XIX?

\section{Abstract}

This unpublished research on the socio-occupational relations and origins of the Uruguayan masons of the 19th century aims to reveal the social bases of Uruguay's Freemasonry. The main documentary sources used were extracted from the main archives of the country together with internal documents of Freemasonry. The structure of the work revolves around the study of three periods, analyzing the nationality, occupations, geographical distribution of lodges and predominance of certain groups in the masonic workshops in order to try to answer the following question: who really integrated freemasonry in 19th Century Uruguay?

\section{Introducción}

El estudio del cosmopolitismo masónico en Uruguay es prácticamente inexistente. No hay registro dentro de la historiografía nacional de que se haya analizado la nacionalidad de los integrantes de la masonería uruguaya en el siglo XIX, ni mucho menos un estudio social. Si recurrimos a la bibliografía elaborada por Ferrer Benimeli observamos que existen pocos trabajos serios que analicen la cuestión masónica. El historiador Mario Dotta es un investigador de referencia en este campo, pero tampoco profundiza en los estudios del cosmopolitismo masónico. También tenemos las investigaciones de Alfonso Fernández Cabrelli, que apuntan más a desentrañar posibles vinculaciones entre los 
revolucionarios independentistas y las ideas masónicas. Luego existen otros estudios más contemporáneos, pero que no logran conformar un rígido estudio académico.

El presente artículo tiene como fin ilustrar acerca de la composición de las logias masónicas uruguayas del siglo XIX, intentando responder las siguientes preguntas: ¿Cuál era la nacionalidad de estos primeros masones? ¿A qué se dedicaban en su mayoría? ¿Pertenecían a estamentos sociales elevados o, más bien, bajos? ¿Qué tan fuerte fue el factor "extranjero" en la masonería nacional del siglo XIX?

El enfoque de la investigación resulta -a mi entender- innovador y original, puesto que es el primero que pretende responder las interrogantes antes planteadas. Para ello recurro a diferentes archivos del país y a documentos masónicos ubicados en la Biblioteca Nacional. En la primera parte se analiza, a modo de introducción, un resumen sobre la historia de la masonería nacional durante sus primeros años de vida. En la segunda parte se realiza un análisis de los integrantes de 67 logias masónicas ubicadas temporalmente entre 1827 y 1893, el primer año corresponde a la fundación de la "logias madre" de la masonería uruguaya y el segundo refiere a la fecha de fundación de la última logia uruguaya del siglo XIX. En la tercera parte se concluye el trabajo con un balance acerca de la estructura social y humana de la masonería uruguaya y del factor extranjero en sus logias, además de comparar esos resultados con la masonería argentina y costarricense.

\section{Inicio y desarrollo de la masonería en el Uruguay}

Pues bien, la respuesta se encuentra en 1807, durante la invasión inglesa a Montevideo. El primer oriental iniciado fue Miguel Furriol y su certificado fue dado a conocer a la logia Acacia en 1912 por su nieto, como lo atestiguan las siguientes palabras:

Nosotros (se refiere a las autoridades del Gran Oriente del Uruguay) por nuestra parte expresamos que copia fotográfica del presente certificado nos fue cedida por un activo miembro de la logia «Acacia» y que durante largo tiempo estuvo expuesto en el Hall del palacio Masónico; que del estudio de dicho certificado se deducen dos comprobaciones: la primera es que la actividad masónica, organizada en la Banda Oriental tuvo origen en esta logia denominada «Logia de Montevideo» y la segunda que el primer masón iniciado en ella fue el H. Miguel Furriol, el 18 de julio de 1807, Lucis 5807. Fue su nieto, el Il.' y Pod.'. Miguel Furriol ${ }^{1}$, Gdo. 33, Gran Lugarteniente y Gran Maestro de nuestra Obediencia quien entregó dicho histórico documento a nuestra hermana la logia Acacia, que lo conserva como preciado tesoro ${ }^{2}$.

\footnotetext{
${ }^{1}$ Se trata de su nieto y las abreviaturas corresponden a su distinción masónica: Ilustre y Poderoso Miguel Furriol.

2 Alfonso Fernández Cabrelli, La Francmasonería en la independencia de Hispanoamérica (Montevideo: s/d, 1988), 61.
} 
La logia que inició a Miguel Furriol fue la $\mathrm{N}^{\circ} 192$ perteneciente al $47^{\circ}$ Regimiento irlandés. Ahora bien, cabría preguntarse si realmente esta logia itinerante fue el origen de la masonería en Uruguay, tal como se afirma en el documento citado. Lo cierto es que este taller fue una logia itinerante que no dejó otras logias en la ciudad de Montevideo y las primeras logias nacionales creadas no tienen ningún tipo de relación con la $\mathrm{N}^{\circ} 192$. Era costumbre que los regimientos británicos tuvieran en su interior logias itinerantes que se trasladaban con el ejército, lo cual constituyó un elemento de expansión de la masonería inglesa. Desde 1807 hasta 1827 no existen registros sólidos de presencia masónica en la región. Como se explicó anteriormente las sociedades actuantes en este período responden a sociedades patrióticas y secretas, que no se adaptan a los requisitos estipulados en la constitución de Anderson para conformar una sociedad masónica.

Precisamente el origen de la masonería uruguaya tiene lugar en la tercera década del siglo XIX cuando ya existía un país independiente. Por esta razón se puede afirmar que no fue la masonería la causante de la independencia, como muchos afirman sin sustento, sino que, por el contrario, el país independiente fue la causa del origen de la institución.

Posteriormente con la creación de las primeras logias nacionales, Asilo de la Virtud y Constante Amistad, ambas en Montevideo, la masonería crece en afiliados y comienza a asentarse en el territorio. Sin embargo, con los primeros enfrentamientos en la llamada guerra grande, la masonería se estancó y decidió cerrar sus templos: “...se comenzó a resquebrajar la vida institucional de la República y para que la Fraternidad no se viera afectada por los acontecimientos los componentes de ambas Logias entornaron sus puertas"3.

Luego de la guerra, la institución renace y entre 1852 y 1856 se forman nuevas logias y se afilian más masones. Finalmente en 1856 se crea el primer órgano nacional masónico denominado Gran Oriente y Supremo Consejo del Uruguay, generalmente llamado Gran Oriente del Uruguay. A partir de este momento la institución va a llevar a cabo una fuerte expansión por todo el país.

Los hechos más notables que cabe destacar entre 1856 y 1893, es decir entre el inicio del Gran Oriente del Uruguay hasta la creación de la última logia uruguaya en el siglo XIX, son la promulgación del código masónico de 1864 bajo la administración del gran maestro Florentino Castellanos ${ }^{4}$, donde se estipularon las principales cuestiones administrativas, algunas de las cuales siguen vigentes hasta el presente.

\footnotetext{
${ }^{3}$ Estas palabras aparece en un documento interno de la masonería y es citado en Alfonso Fernández Cabrelli, Iglesia Ultramontana y Masonería en la transformación de la sociedad oriental (Montevideo: América Una, 1990), 165.

${ }^{4}$ Código Masónico para las Oficinas del Circulo del Gran Oriente del Uruguay (Montevideo: Imprenta tipográfica a vapor, 1864).
} 


\section{Imagen 1}

Caratula del primer codigo masónico de la obediencia uruguaya

\section{CÓDIGO}

며성 (1) (1)

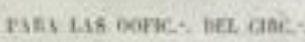

DEL GR. OR. DEL, URUGU.

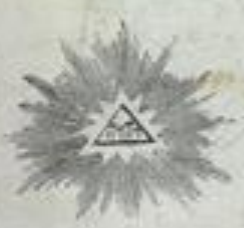

MONTEVIDEO

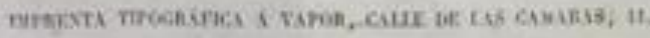

\section{4.}

Fuente: Biblioteca Nacional, sección de documentos especiales, Sala Uruguay.

Un aspecto interesante de este código son los derechos que los afiliados obtienen por pertenecer a la institución, estos son:

$1^{\circ}$ Fidelidad recíproca y socorro individual, haciéndose extensivo este socorro y protección á sus viudas é hijos menores, y aún mayores en estado de indigencia.

$2^{\circ}$ Aumento de salario ${ }^{5}$ correspondiente á sus talentos y virtudes y á los servicios hechos á la Mason:. Y á la Humanidad en general.

$3^{\circ}$ Elección y elegibilidad para cualquier empleo en relación á los méritos y grados, empezando por el de Maest:.

$4^{\circ}$ Juzgamiento en $1^{\circ}$ y $2^{\circ}$ instancia en la forma establecida en la Parte Penal.

$5^{\circ}$ Petición, cuando la requieran su bienestar é interés.

\footnotetext{
${ }^{5}$ Aumento de grado.
} 
$6^{\circ}$ Reclamación contra cualquier acto ofensivo á su justicia y dignidad, observando las formalidades establecidas ${ }^{6}$.

Otro hecho a destacar de la historia de la masonería uruguaya es la discrepancia que surgió a partir de 1868 entre las logias uruguayas y algunas logias italianas asentadas en Montevideo. El conflicto se dio principalmente con la logia italiana Esperanza y desembocó en que todas las logias extranjeras comenzaron a afiliarse a la institución masónica uruguaya.

La llegada de Carlos de Castro a la cima de la masonería uruguaya auguró grandes logros, entre ellos la construcción del Palacio Masónico (actualmente la sede del museo del ejército nacional) en 1882. Este proyecto tuvo lugar en el terreno que albergaba a la institución, calle Soriano esquina Cuareim, y para constituir el capital necesario para su realización se emitieron 1150 obligaciones hipotecarias, garantidas sobre el terreno y edificio que se construya. La masonería nacional estaba pasando por un momento de auge interno, había aumentado el número de logias y la expansión por el interior del país se estaba llevando a cabo de forma satisfactoria. Un dato que prueba la buena situación de la orden en 1882 es el costo que demandó el Palacio Masónico, 90.000 pesos uruguayos, cifra elevadísima que no todas las instituciones tenían el privilegio de disponer.

Detallemos los materiales que usaron para construir la sede masónica más importante del país. En el primer piso se edificaron pisos de piedra gruesa de Hamburgo, a partir de los cuales se levantaron paredes de ladrillo colorado de $1^{\circ}$ calidad. El costo total de la albañilería fue de 22.000 pesos uruguayos aprox. En lo que respecta a marmolería se utilizó un piso de mármol blanco de Carrara y negro de Hamburgo, además de planchas de mármol para el pretil de cada ventana.

Los trabajos de carpintería fueron más finos si se quiere. Se utilizó un piso de pino de $1^{\circ}$ calidad en las habitaciones que albergarían a la biblioteca, secretaria, tres logias y tres salas de pasos perdidos. Para el segundo piso especificó la construcción de un:

Cielo-raso de material, arena dulce y fina y capa de yeso, con su cornisa á gorgia adornada, formando bóveda en todos los salones cuartos de pasos perdidos, Gran Secretaría y grandes comisiones, con tres rosones en el salón central y uno en cada otro salón y piezas... ${ }^{7}$. Dividiendo por sección los gastos son los siguientes: Primer piso: albañilería: \$22393, marmolería: \$3551, herrería: \$3228, carpintería: \$9059 y accesorios: \$1624. Segundo piso: albañilería: \$27018, marmolería: \$2465, herrería: \$3393 y carpintería: $\$ 10069$.

\footnotetext{
${ }_{7}^{6}$ Código Masónico para las Oficinas del Círculo, 8.

${ }^{7}$ Ley y presupuesto para la construcción del Palacio Masónico (Montevideo: Imprenta a vapor El Ferrocarril, 1882), 11.
} 
Imagen 2

Caratula del proyecto de construcción del palacio masónico.

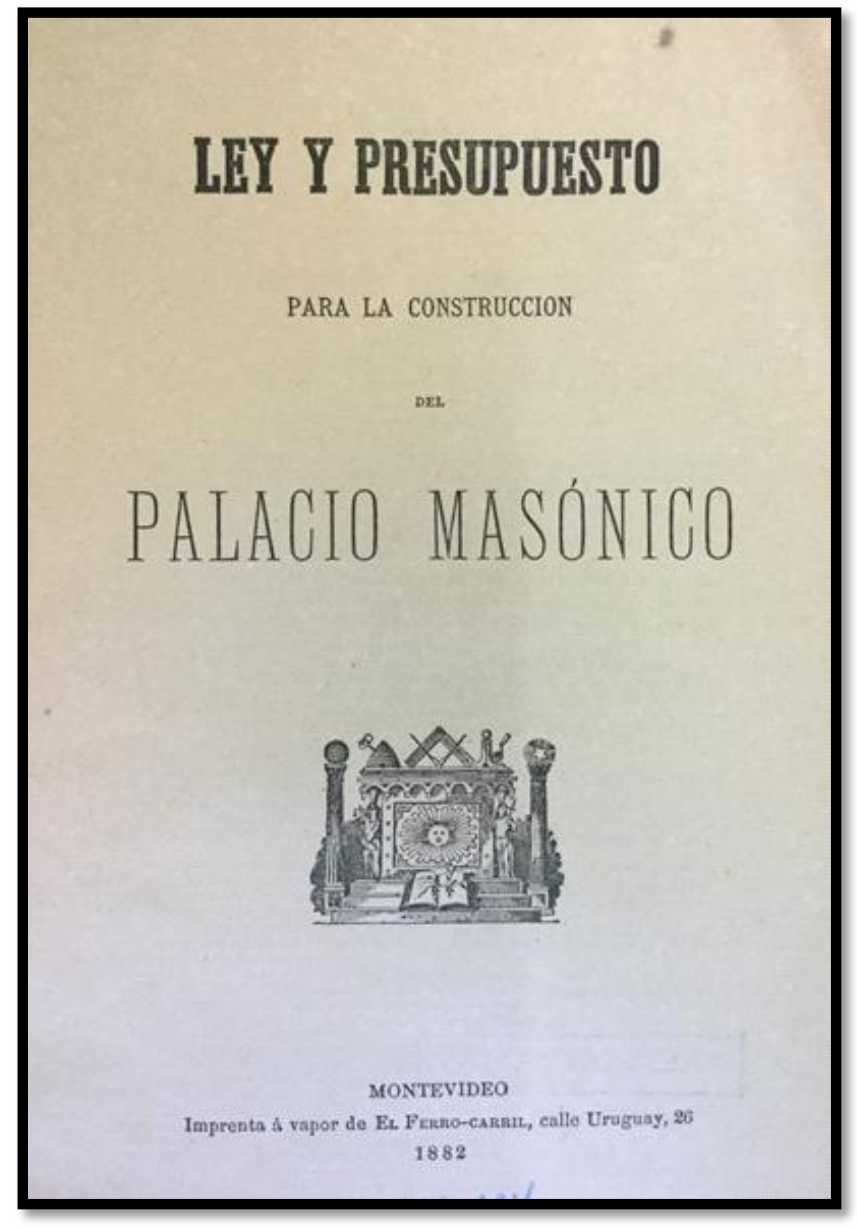

Fuente: La misma de la imagen 1.

La construcción del palacio masónico otorgó a la masonería nacional una sede adecuada para llevar a cabo sus actividades de la forma más efectiva posible. El importante costo que el edificio requirió fue cubierto por todos y cada uno de los integrantes. Esto significa que el asentamiento efectivo de la masonería en el país es un hecho en 1882, sus logias se han reproducido por casi todo el país, dentro de sus logias existen personas de los más diversos estratos sociales y cuenta con la personería jurídica otorgada por el gobierno de Máximo Santos, otro logro del eminente gran maestro Carlos de Castro. La masonería nacional es un hecho. 


\section{Relación socio-ocupacional y procedencia de los masones en Uruguay (1827-1893)}

Es necesario dividir en tres etapas el período estudiado: $1^{\circ}$ etapa, 1827-1860 (desde la creación de la primera logia masónica registrada formada, en su mayoría, por uruguayos hasta la presidencia del Gran Oriente del Uruguay en manos de Florentino Castellanos, impulsor del código masónico nacional), $2^{\circ}$ etapa 1861-1880 (a partir de la administración de Florentino Castellanos hasta plena administración de Carlos de Castro, impulsor del reconocimiento institucional de la masonería y creador de la constitución masónica de 1882) y $3^{\circ}$ etapa 1881 - 1893 (desde la fructífera administración de Carlos de Castro hasta el año donde se fundó el ultimo taller masónico del siglo XIX bajo la jurisdicción uruguaya. De esta forma se observa claramente los índices de relación socio-ocupacional y nacionalidad de los integrantes.

\section{$1^{\circ}$ Etapa $1827-1860$}

En la primera etapa (1827-1860) la masonería nacional asistió a su origen y a su formación organizacional. Es una etapa muy importante, no solo por el alto número de extranjeros en las filas de la hermandad, sino también por la rápida expansión que se llevó a cabo en el interior del país. Entonces, ¿De qué nacionalidad provenían los masones del extranjero? Luego de un exhaustivo análisis de documentos originales he podido identificar las siguientes nacionalidades: escoceses, ingleses, españoles, estadounidenses, brasileños, argentinos, italianos, franceses, portugueses, prusianos y alemanes.

El abanico de nacionalidades es por demás interesante. Ahora, si nos enfocamos en el factor cuantitativo de estos masones en las logias, observamos que de un total de 22 logias nacionales existentes entre 1827 y 1860 y 194 masones identificados la distribución de nacionalidades se da de la siguiente forma: 


\section{Gráfico 1}

Número de masones respecto a nacionalidad

estadounidenses, 1

ingleses, 2

portugueses, 6

escoceses, 7

alemanes, 7

franceses, 10

brasileños, 10

argentinos, 21

italianos, 28

españoles, 41

uruguayos, 61

Fuentes: Archivo General de la Nación, archivos privados: Carlos de Castro (1855-1905); Archivo de Biblioteca Nacional, sección de documentos especiales, Sala Uruguay; y Miguel Salsamendi, Crónicas del levantamiento de Columnas de las Logias nacidas bajo jurisdicción masónica uruguaya y datos biográficos de sus fundadores, desde el 21 de enero de 1830 al 30 de junio de 2000 (Montevideo: Gran Logia de la Masonería del Uruguay, 2001).

Las logias con predominio de extranjeros superan a las logias con predominio uruguayo en una escala de 14 a 8 . Es innegable que el factor humano extranjero tuvo un rol notable en los primeros años de vida de la masonería uruguaya. Una de las causas que pueden ser adjudicadas a este fenómeno es la fuerte inmigración que tuvo lugar en el Uruguay luego del fin de la guerra grande en 1851. Es evidente que inmigración y masonería están unidas.

Ahora bien, sigamos estudiando el factor humano e intentemos responder a la siguiente pregunta: ¿Qué tipo de ocupaciones laborales poseían los masones en esta etapa? 


\section{Gráfico 2}

Número de masones respecto a ocupaciones

Aduaneros, 1

Caligrafos, 1

Jefes polticos, 1

Comandantes de

prefectura, 1

Prácticos del río, 1

Sacerdotes, 1

Diplomáticos, 2

Ebanistas, 2

Educadores, 3

Farmacéuticos, 3

Literatos, 4

Contadores, 4

Agrimensores, 4

Ministros de

Estado, 4

Ingenieros, 5

Procuradores, 5

Corredores, 5

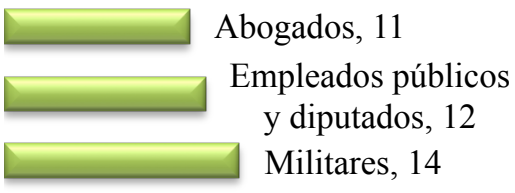

Médicos y

hacendados, 44

Comerciantes, 66

Fuentes: Las mismas del gráfico 1.

El número de comerciantes en las logias masónicas de esta primera etapa es abrumador, a tal punto que en cada uno de los 22 talleres relevados durante estos años siempre existen dos o más comerciantes. No es casualidad que sean la ocupación más presente, puesto que Uruguay siempre ha tenido en cuenta la importancia de contar con un comercio fluido hacia el extranjero. Basta con observar las palabras contenidas en un informe oficial de 1791: 
...en 1792 consta haber entrado en Montevideo procedentes de España y África, 67 embarcaciones y salido 69, conduciendo aquellas en frutos nacionales y extranjeros por valor de 2.993.267 pesos fuertes ${ }^{8}$, y estos exportaron en plata y frutos del país por 4.790 .094 pesos fuertes... Desde entonces hasta la fecha ha seguido aumentando la navegación habilitada del puerto de Montevideo o comprando para ello los comerciantes las embarcaciones que han podido alcanzar, ya construyéndolas en Buenos Aires o Río Paraguay y ya, traídas de Brasil ${ }^{9}$.

El comercio era uno de los rubros más elegidos para los habitantes del Montevideo de principios del siglo XIX, ¿es posible que el alto porcentaje de extranjeros en las logias masónicas uruguayas fuera propiciado fundamentalmente por la fuerte actividad del puerto de Montevideo? En lo que respecta a esta investigación, todo indica que si, puesto que dicho puerto fue la principal puerta de entrada de inmigrantes en todo el país, como se verá más adelante.

A principios del XIX constatamos los persistentes progresos del masonismo montevideano, empujes que se acompasan con el intensificado aumento en la importancia comercial y poblacional del puerto y el territorio. Ambas cosas se comprenden muy bien teniendo en cuenta la atracción que, en especial Montevideo, representaba para los hombres de empresa y aventura conocedores de la importancia que había adquirido nuestro puerto y las posibilidades de buenos negocios que ofrecían los productos naturales de nuestra comarca interior, así como las crecientes necesidades que la nueva expansiva sociedad tenía de mercaderías y esclavos ${ }^{10}$.

En lo que respecta a las profesiones liberales, destacan los médicos y un porcentaje menor de abogados. Sin embargo un dato interesante, a mi juicio, es el alto número de hacendados en las filas de la masonería. Si en Montevideo existían logias repletas de comerciantes, en el interior del país esa misma dimensión va a ser ocupada por terratenientes y comerciantes. Desde el punto de vista económico, la masonería uruguaya en esta etapa gozó de una excelente situación financiera. Afirmación que puede ser corroborada con las cifras que demuestran la rápida expansión de la orden por todo el territorio nacional.

Prosigamos con la distribución geográfica de las 22 logias nacionales registradas, las cuales presentaban la siguiente ubicación: Canelones, Salto (2 talleres), Durazno, Paysandú (2 talleres), Tacuarembó, San José y Cerro Largo.

$\mathrm{Si}$ tenemos en cuenta que Uruguay en 1860 contaba con 13 departamentos (actualmente cuenta con 19) se puede afirmar que la masonería tenía presencia en la mitad

\footnotetext{
${ }^{8}$ Moneda de la época.

${ }^{9}$ Documento hallado en el Museo Histórico Nacional y citado en Fernández Cabrelli, Alfonso, Masones y Artiguistas en la Banda Oriental (Montevideo: s/d, 1986), 39.

${ }^{10}$ Fernández Cabrelli, Masones y Artiguistas, 38.
} 
del territorio nacional. También existe documentación de la creación de talleres en el exterior, principalmente en Argentina.

Respecto a la hegemonía de ciertas ocupaciones en las distintas logias, existe un alto predominio de la clase comercial frente al resto de ocupaciones. De las 13 logias que presentan esta característica, 6 se ubican en la capital del país, mientras que las 7 restantes se asientan en el interior, preferentemente en la zona litoral, es decir, el área uruguaya que limita con Argentina. Es clara la relación entre el comercio binacional y los comerciantes masones.

\section{$2^{\circ}$ etapa $1861-1880$}

Tal como se proyectó en la primera parte, observemos las distintas nacionalidades que figuran en las logias masónicas de esta segunda etapa: españoles, estadounidenses, suecos, italianos, alemanes, daneses, franceses, brasileños, portugueses, polacos, argentinos, ingleses, suizos y griegos.

Respecto a la etapa anterior no aparecen ni escoceses ni prusianos, aunque ven la luz nuevas procedencias como griegos, suizos, polacos, suecos y daneses. Existe un incremento en el número de masones identificados, esta vez son 247 miembros conformados en 19 logias. 


\section{Gráfico 3}

Número de masones respecto a nacionalidad

griegos, 1

polacos, 2

suecos, 2

estadounidenses, 2

suizos, 3

daneses, 3

portugueses, 4

alemanes, 5

argentinos, 6

ingleses, 7

brasileños, 12

franceses, 29

uruguayos, 54

italianos, 54

españoles, 63

Fuentes: Las mismas del gráfico 1.

Esta vez el número de logias con predominio español supera a los talleres con predominio uruguayo. Hay un aumento de extranjeros, tanto de franceses como italianos. Si sumamos todas las logias con mayoría extranjera da como resultado la cifra de 13 talleres frente a los 6 con mayoría uruguaya. También llama la atención la cantidad de masones de procedencia brasileña que supera (hasta desplazar) a los masones argentinos que si tenían un lugar en la gráfica de la primera etapa. Veamos la relación ocupacional: 


\section{Gráfico 4}

Número de masones respecto a ocupaciones

Otros, 31

Odontólogos, 2

Panadeos, 2

Cónsules, 2

Corredores, 2

Artesanos, 2

Industriales, 3

Estibadores, 3

Prácticos del río, 3

Plateros, 3

Ingenieros, 3

Pintores, 3

Marinos, 5

Procuradores, 5

Militares, 7

Empleados

Públicos, 7

Médicos, 8

Farmacéuticos, 8

Sastre, 9

Carpinteros, 15

Educadores, 17

Hacendados, 28

Comerciantes, 79

Fuentes: Las mismas del gráfico 1.

Nuevamente los comerciantes se colocan en la cima de las profesiones más repetitivas de los masones del siglo XIX. Le siguen de cerca los hacendados que se posicionan en el segundo puesto, desplazando a los médicos que en esta segunda etapa tienen una presencia muchísimo menor que en la primera. Los sastres y carpinteros forman un fuerte núcleo de masones, principalmente integrando logias italianas que luego pasaron a la órbita del Gran Oriente del Uruguay.

Un factor que refuerza la idea de que la masonería uruguaya del siglo XIX poseía en su seno a integrantes de diversas capas sociales, es la documentación que testifica la 
presencia de un conde polaco en la nómina de una logia de Tacuarembó (departamento ubicado en el noreste de Uruguay). Fíjese el lector la importancia de la masonería como aglutinador de personas de diferentes estratos. En una logia coexisten zapateros, sastres y carpinteros con industriales, comerciantes y hacendados. ¿Cuántas instituciones en el Uruguay del siglo XIX poseían tal cualidad? Me atrevo a afirmar que casi ninguna. La masonería uruguaya, desde sus inicios, supo integrar realmente a personas de diferentes creencias, posición social y profesión, lo que generó que se dieran algunos hechos sorprendentes, como por ejemplo, mientras se desarrollaba la guerra civil de 1904 que enfrentó a blancos y colorados (militantes de los principales partidos políticos) existían logias que poseían en su nómina a sujetos de estos dichos bandos.

Los talleres masónicos ubicados en el interior se asientan en las siguientes localidades: Soriano (3 logias), Treinta y Tres, Tacuarembó (2 logias), Artigas, Lavalleja, Cerro Largo, Salto (2 logias), Florida y Paysandú.

Después de analizar estos datos afirmo que la masonería uruguaya procedió a un estancamiento en su expansión territorial respecto a la primera etapa.

La novedad radica en que hay una logia con un alto número de militares, ubicada en el interior del país, y otro taller con predominio de educadores también establecido en el interior. En lo referente a las logias con altos índices de comerciantes los documentos indican que se tratan de talleres ubicados principalmente en el interior (exactamente 7 logias) frente a los 5 restantes de la capital.

\section{$3^{\circ}$ etapa $1881-1893$}

Esta última etapa de la masonería uruguaya del siglo XIX representa un periodo de recuperación expansiva, tanto en la fundación de logias como en el aumento de masones identificados. Observemos primeramente las nacionalidades presentes en este lapso de tiempo: españoles, argentinos, italianos, suizos, prusianos, franceses, alemanes, portugueses, irlandeses, brasileños, ingleses y paraguayos.

La principal modificación respecto a la etapa anterior es la reincorporación de la nacionalidad prusiana y la aparición de miembros paraguayos. Esto último tiene su causa en que la obediencia masónica uruguaya emitió cartas patentes para la formación de talleres en Paraguay.

En este periodo encontramos 26 logias nuevas y un total de 333 masones identificados. ¿Cuál es la evolución de la presencia de extranjeros en los mencionados talleres? 


\section{Gráfico 5}

Número de masones respecto a nacionalidad

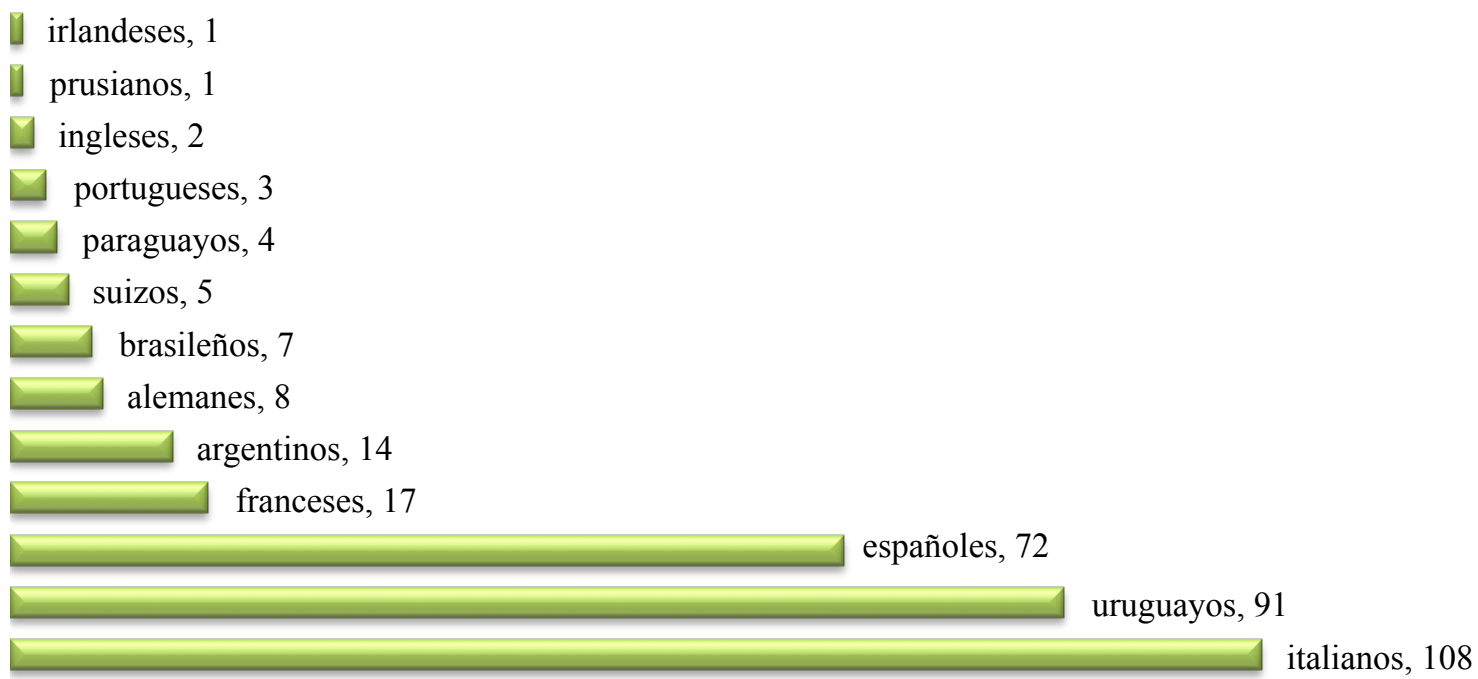

Fuentes: Las mismas del gráfico 1.

La relación entre predominio extranjero y nacional es 19 a 7 a favor del primero, siendo la etapa donde más extensión existe entre los dos grupos. El núcleo español sigue siendo el predominante, tal como sucedió en la etapa anterior. También los italianos conforman un aspecto importante en la masonería nacional, ambas nacionalidades: tanto la española como la italiana son el flujo principal en las corrientes de inmigrantes que llegan a las costas uruguayas.

Observemos ahora la relación ocupacional: 


\section{Gráfico 6}

Número de masones respecto a ocupaciones

Zapateros, 4

Marinos, 4

Joyeros, 4

Industriales, 5

Agrimensores, 5

Carpinteros, 6

Escribanos, 6

Médicos, 7

Farmacéuticos, 8

Procuradores, 9

Pintores, 10

Sastres, 11

Educadores, 17

Hacendados, 19

Militares, 21

Empleados

públicos, 27

Otros, 55

Comerciantes, 115

Fuentes: Las mismas del gráfico 1.

La evaluación ocupacional de la masonería uruguaya a fines del siglo XIX arroja estos sorprendentes resultados. Pasando por alto al grupo más fuerte, el comerciante, se vislumbra el sector de los empleados públicos, en segundo lugar, y seguidamente encontramos a militares, educadores y hacendados. Para el caso de los comerciantes está claro que han constituido el sector más populoso de la masonería uruguaya en todo el siglo XIX. Respecto a los empleados públicos es la primera vez que cuentan con un lugar de predominio dentro de la masonería, esto va acompañado de un crecimiento y solidificación de los servidores públicos.

Llama la atención el pequeño número de ministros y mandatarios presentes. Aun así debo afirmar que los presidentes que he identificado se encuentran en una logia de Paraguay y fueron mandatarios de ese mismo país. Se trata de Bernardino Caballero, Juan Gualberto González y Patricio Escobar. 
Las logias ubicadas en el exterior corresponden a Concepción del Paraguay y 2 en Asunción del Paraguay. Los talleres establecidos en el interior del país tienen un gran crecimiento y llegan a 14 distribuidos en las siguientes localidades: Rocha (2 talleres), Colonia, Paysandú, Artigas, Salto, Maldonado, Colonia (3 talleres), San José, Canelones, Treinta y Tres, y Río Negro.

Es un hecho que la masonería en el interior creció de manera considerable. No hay que olvidar que durante estos años sucede el primer mandato Carlos de Castro como cabeza de la orden en Uruguay, una persona de fuerte carácter y convicción que llevó a la masonería a una posición favorable tanto en lo concerniente al exterior (tratados de amistad y constante dialogo con otras potencias masónicas) como en lo interior (promulgación de la Constitución de 1882 y reconocimiento jurídico por parte del Poder Ejecutivo en ese mismo año).

De las 21 logias con predominio de comerciantes un $50 \%$ están establecidas en el interior del país, un $40 \%$ en la capital y un $10 \%$ en el exterior (Paraguay). Los empleados públicos se encuentran básicamente en el interior, mientras que la logia con predominio de políticos es extranjera, nuevamente en Paraguay. Los hacendados también se ubican en el interior y los industriales en la capital.

\section{Cuadro 1}

Integrantes de Asilo de la Virtud al momento de su fundación irregular en 1827

\begin{tabular}{|c|c|c|c|}
\hline Nombre & Lugar y fecha de nacimiento & Ocupación & Grado \\
\hline Gabriel Pérez & $\begin{array}{l}\text { Montevideo, } 18 \text { de noviembre de } \\
1795\end{array}$ & $\begin{array}{l}\text { Diplomático, cónsul en Rio de } \\
\text { Janeiro }\end{array}$ & 18 \\
\hline Antonio Acuña & Uruguay el 25 de junio de 1794 & Coronel & 3 \\
\hline José María Platero & España el 28 de enero de 1793 & Comerciante & 3 \\
\hline Juan Pedro González & Uruguay el 24 de junio de 1792 & Escribano & 3 \\
\hline Eduardo Mac Eachen & Escocia el 12 de febrero de 1801 & Comerciante & - \\
\hline Jonathan Tabor Fox & Londres en 1806 & $\begin{array}{l}\text { Contador, interventor de la } \\
\text { Aduana }\end{array}$ & 3 \\
\hline $\begin{array}{l}\text { Jorge Pedro Enrique } \\
\text { Tornquist }\end{array}$ & $\begin{array}{l}\text { Estados Unidos el } 15 \text { de agosto de } \\
1801\end{array}$ & Cónsul & 18 \\
\hline Francisco Lecocq & Uruguay en 1790 & Hacendado & 3 \\
\hline Joaquín de Chopitea & Uruguay el 22 de marzo de 1796 & Coronel & 3 \\
\hline Tomás Dutton & Uruguay & Comerciante & 3 \\
\hline Patricio Mac Lean & Escocia & Comerciante & 3 \\
\hline
\end{tabular}

La masonería uruguaya funcionó como un escenario donde podían incluirse diferentes culturas, pensamiento y accionar. Esto constituyó una ventaja para la institución uruguaya, puesto que pocas organizaciones en el siglo XIX podían permitirse incluir en su interior personas de los más diversos orígenes geográficos y sociales. Para poder ilustrar mejor este aspecto voy a identificar a los integrantes de la primera logia nacional registrada, 
Asilo de la Virtud, con sede en Montevideo y a los miembros de la logia Santa Rosa de Lima, creada en 1857 con sede en Tacuarembó, localidad concentrada en el noreste del país.

En los registros de la primera logia nacional se identifican 11 miembros, de los cuales 6 nacieron en Uruguay, mientras que los restantes 5 son extranjeros. Respecto a las ocupaciones laborales prevalecen los comerciantes, pero también existen cónsules, escribano, militares y un hacendado. Respecto al promedio de edad se constata alrededor de los 29 años, lo cual induce a suponer que se trata de un taller joven.

La masonería uruguaya se establece institucionalmente en 1856 y la logia Santa Rosa de Lima se crea en el interior del país un año más tarde. Observemos su relación de integrantes.

Cuadro 2

Integrantes de Santa Rosa de Lima al momento de su fundación en 1857

\begin{tabular}{|l|l|l|c|}
\hline Nombre & Lugar de nacimiento & Ocupación & Grado \\
\hline Juan Bautista Oliva & Italia & comerciante & 18 \\
\hline Juan Pedro Ortega & Uruguay & procurador & 3 \\
\hline José Ignacio Acosta & Brasil & comerciante & 3 \\
\hline Miguel Jofre & Argentina & propietario & 3 \\
\hline Antonio Segul & España & escribano & 3 \\
\hline José Benito Trigo & España & comerciante & 3 \\
\hline José Antonio Poggi & Uruguay & procurador & 3 \\
\hline Luis Conzi & Italia & farmacéutico & 3 \\
\hline Antonio Sghirla & Italia & comerciante & 3 \\
\hline Juan Bautista Castro & Uruguay & hacendado & 3 \\
\hline Fructuoso L. Pittaluga & Uruguay & abogado y propietario & 1 \\
\hline Joaquín Herrera & Uruguay & militar & 1 \\
\hline Carlos Escayola & Uruguay & propietario y coronel & 1 \\
\hline Ramón José González & Uruguay & empleado & 1 \\
\hline Fructuoso Gilbert & Uruguay & comerciante & 1 \\
\hline Cipriano G. Semeria & Uruguay & empleado público & 1 \\
\hline Luis Conti & Uruguay & militar & 1 \\
\hline Antonio Abella & España & comerciante & 1 \\
\hline José Uria & España & comerciante & 1 \\
\hline Enrique Poggi & Uruguay & empleado & 1 \\
\hline José Leonart & España & comerciante & 1 \\
\hline Francisco Cavagliatti & Italia & comerciante & 1 \\
\hline Celestino Gastellu & Francia & comerciante & 1 \\
\hline Esteban Semeria & Uruguay & 1 \\
\hline Tomás Wagner & Brasil & 1 \\
\hline Fuentes: las mismas dele gráfico 1. & & \\
\hline & & & 1 \\
\hline
\end{tabular}

Como el lector puede apreciar, el número de masones identificados en este caso se eleva a 25 , lo cual representa un aspecto interesante a destacar, ya que varias logias masónicas ubicadas en la capital del país no alcanzaban dicha cifra. 
Respecto a las nacionalidades, la evidencia documental demuestra que 12 de los 25 miembros nacieron en Uruguay, mientras que los restantes son provenientes del extranjero, principalmente de España e Italia. Esto último no es ninguna sorpresa si se analizan los índices de inmigración del Uruguay a mediados del siglo XIX.

Sobre las ocupaciones, destaca el grupo de los comerciantes que eleva a 12 el número de integrantes, casi la mitad de la composición de la logia. Sin embargo, llama la atención la baja presencia de hacendados, considerando que se trata de un taller masónico del interior del país y en un departamento con fuerte tradición agropecuaria.

Como mencioné líneas arriba, el puerto de Montevideo ha tenido principal importancia en el influjo de inmigrantes a Uruguay, lo que a su vez incidió, en mayor o menor medida, a que en los templos masónicos hubiera una suma cuantiosa de extranjeros. Uno de los historiadores que ha estudiado los índices de inmigración es Eduardo Acevedo, donde en el tercer tomo de su libro titulado Historia del Uruguay, se brindan algunos datos que explican la importancia del factor extranjero en el país.

Inmigrantes desembarcados en Montevideo entre 1835 y $1841^{11}$

Vascos, franceses y españoles...............................8389

Canarios, gallegos y catalanes.............................7781

Genoveses............................................. 4058

Brasileños...........................................1011

Otras nacionalidades....................................772

También si se observa el movimiento portuario de Montevideo se aprecia la magnitud y el crecimiento prolongado del comercio extranjero, factor importante en el proceso de inmigración.

\begin{tabular}{|c|c|}
\hline \multicolumn{2}{|c|}{ Movimiento portuario } \\
\hline Años & Buques mercantes arribados \\
\hline 1836. & …...........335 \\
\hline 1837. & ..........374 \\
\hline 1838 & ....495 \\
\hline 1839 & ....512 \\
\hline 1840 & ....700 \\
\hline 1841 & $\ldots 789$ \\
\hline 1842. & ....824 \\
\hline
\end{tabular}

${ }^{11}$ Datos extraídos de Eduardo Acevedo, Historia del Uruguay tomo 3 (Montevideo: Imprenta Nacional, 1919). 


\section{Comparación con los casos argentino y costarricense}

Gracias a la investigación de Claudio Giménez "Masonería y cosmopolitismo en la Argentina de finales del siglo XIX"12 se puede entablar cierto paralelismo con el caso uruguayo. En primer término, el investigador menciona que existen logias que poseen una exclusiva nacionalidad, como es el caso de Unione Italiana, del año 1867, formada en su mayoría por italianos. Pues bien, en Uruguay también existen logias de este tipo como es el caso de Les Enfants Du Nouveau Monde (posteriormente denominada Les Amis de la Patrie) establecida en 1827 y conformada en un $95 \%$ por franceses. También es el caso de varias logias adheridas al Gran Oriente de Italia que estaban instaladas en Uruguay y posteriormente solicitaran ingresar al Gran Oriente de Uruguay.

En lo referente a los oficios, Giménez menciona: “...la masonería tenía un amplio cosmopolitismo y se fue acrecentando a medida que llegaban inmigrantes al país, hasta les permitió a las colectividades tener sus propias logias. También vemos que no hay distinción de profesión todos están comprendidos en las logias"13.

La masonería uruguaya del siglo XIX también poseía un fuerte cosmopolitismo, como hemos observado en el análisis de los integrantes de sus logias, y también se puede afirmar que no había distinción de profesiones ni desprecio por ninguna nacionalidad. En una misma logia se podía encontrar todo el espectro de la sociedad y, además, personas que provenían de varios puntos del planeta. De esta forma podemos responder a la pregunta que muchos se hacen ¿la masonería del siglo XIX era aristocrática? Para nada y es el mismo Claudio Giménez quien procede a contestarla:

Vemos que en las logias hay tanta pluralidad de patrias como de empleos, desde estancieros hasta zapateros, pasando por toda la gama posible de trabajos sin distinción alguna y deducimos que la masonería no es oligárquica, sino en cambio abarca todos los sectores de la sociedad, tanto en forma social como económica y política $^{14}$.

El claro cosmopolitismo de la masonería uruguaya y argentina se deja ver en los innumerables documentos relativos a la conformación social de las logias. Este es un aspecto que se olvida, ya que se trata de observar a la orden como una especie de club privado elitista, tratando constantemente de vincular a los próceres y héroes de la historia nacional con la masonería y olvidando cuáles fueron sus auténticos orígenes y bases.

\footnotetext{
${ }^{12}$ Claudio Ariel Giménez, "Masonería y cosmopolitismo en la Argentina de finales del siglo XIX", en Nueva Historia de las redes masónicas atlánticas, coor. Dévrig Mollés (La Plata: Editorial de la Universidad de La Plata, 2012), 227-268.

${ }^{13}$ Ariel Giménez, Masonería y cosmopolitismo, 251.

${ }^{14}$ Ariel Giménez, Masonería y cosmopolitismo, 265.
} 
Si bien es cierto que el carácter cosmopolita de la masonería uruguaya se da antes del aluvión inmigratorio, una vez que este llega, las logias comienzan a absorber a gran cantidad de extranjeros de diferente procedencia. La institución masónica uruguaya procuró desde el primer momento brindar un espacio de integración, soporte y socorro para todos los integrantes, tal como lo afirma el artículo primero del capítulo de derechos masónicos que compone el código masónico de 1864: "1 Fidelidad recíproca y socorro individual, haciéndose extensivo este socorro y protección á sus viudas é hijos menores, y aún mayores en estado de indigencia" 15 .

Masonería, cosmopolitismo e inmigración van de la mano y a lo largo de este artículo hemos visto de qué manera se conformaron las logias uruguayas del siglo XIX, quienes las integraban y de donde prevenían. Por esta razón puedo afirmar que la masonería nacional fue una construcción de personas de los más diversos extractos sociales y nacionalidades. Sin dudas que esta afirmación está lejos de aquellas que consideran a la masonería como un lugar de elite económica únicamente, nada más lejos de la verdad.

En el caso de la comparación con la masonería en Costa Rica, utilizo el libro de Ricardo Martínez Esquivel titulado Masones y masonería en la Costa Rica de los albores de la Modernidad (1865-1899) ${ }^{16}$. Allí se encuentran datos interesantes sobre el carácter cosmopolita de la sociedad masónica que le permitía: “... funcionar como un espacio de sociabilidad que permite la integración de personas de distintas nacionalidades" ${ }^{\prime 17}$. El caso uruguayo muestra una semejanza importante con Costa Rica, puesto que las gráficas esbozadas líneas arriba evidencian un alto porcentaje de extranjeros en los registros de las logias masónicas. Por tanto, cabe hacerse la siguiente pregunta ¿Por qué existe tanta cantidad de extranjeros en la masonería? Según Martínez Esquivel la masonería para el caso costarricense “...funcionó como un espacio de inserción social, sociabilidad e identidad para los inmigrantes en la sociedad costarricense, quienes en su mayoría provinieron de países con tradición masónica" ${ }^{\text {"18 }}$. Si bien es cierto que los masones uruguayos del siglo XIX seguían este perfil cosmopolita, existe una diferencia profunda con el caso costarricense que Martínez Esquivel señala en su trabajo académico: la condición económica de los masones.

Según el investigador costarricense la masonería en aquel país presentó las siguientes características:

La sociedad masónica en Costa Rica simbolizó una comunidad de fuerte carácter excluyente, exclusivista y de ingreso restringido, situación ambivalente dentro de su

\footnotetext{
${ }^{15}$ Código Masónico para las Oficinas del Circulo del Gran Oriente del Uruguay (Montevideo: Imprenta tipográfica a vapor, 1864).

${ }^{16}$ Ricardo Martínez Esquivel. Masones y masonería en la Costa Rica de los albores de la Modernidad 18651899 (San José: Editorial de la Universidad de Costa Rica, 2017), 109.

${ }^{17}$ Martínez Esquivel, Masones y masonería, 109.

${ }^{18}$ Martínez Esquivel, Masones y masonería, 110.
} 
discurso de igualdad y auto representación como centro de formación humanística. La masonería costarricense solo estuvo abierta a personas con cierto capital o posición social. El análisis prosopográfico ha permitido ha permitido identificar que los miembros de los talleres masónicos corresponden a personas de sectores económicos medios y altos de la sociedad costarricense ${ }^{19}$.

Quizás este aspecto represente la gran diferencia entre la composición de la masonería uruguaya y la masonería costarricense. En las logias del primer caso se pueden ubicar masones de todos los extractos sociales y de distintas profesiones, desde comerciantes y hacendados, hasta zapateros y herreros. La distinción fundamental de los masones uruguayos del siglo XIX era que componían una sociedad que intentaba representar a todos los niveles de la sociedad. Veamos un ejemplo en la integración de la logia Progreso Social, establecida en Montevideo en el año 1872:

Cuadro 3

Miembros de la logia Progreso Social de Montevideo

\begin{tabular}{|l|l|l|}
\hline Nombre & Lugar y fecha de nacimiento & Ocupación \\
\hline Federico Fernandez Calvet & España, el 7 de noviembre de 1833 & Profesor de Instrucción Pública \\
\hline Juan de Dios Paz & España & Repartidor de diarios \\
\hline Manuel Freire & España, el 30 de abril de 1830 & Comerciante, dueño de una sastrería \\
\hline Andrés Dubra y Seoane & España, el 24 de octubre de 1838 & Preceptor \\
\hline Nicolás Taborcia & sin datos & sin datos \\
\hline Antonio Suarez Magariños & sin datos & sin datos \\
\hline Antonio Varela & sin datos & sin datos \\
\hline Andrés Barosela & España & Sastre \\
\hline Juan Cazot & Argentina & Militar \\
\hline Vicente Porcile & Uruguay & Herrero \\
\hline Francisco Quintana & España & Comerciante \\
\hline Andrés Rosso & Italia & Comerciante \\
\hline Emiliano Crespo & España & Comerciante \\
\hline Pedro Arregui & sin datos & sin datos \\
\hline Manuel G. Ribera & España & Preceptor y Balanceador \\
\hline José María López & España, el 8 de noviembre de 1844 & Curial \\
\hline Juan Llovet y Castellet & España & Artista \\
\hline Lázaro Boeri & Italia, el 25 de mayo de 1827 & Artesano \\
\hline Rodolfo Ziegler & sin datos & sin datos \\
\hline $\begin{array}{l}\text { Fuentes: Archivo General de la Nación, archivos privados: Carlos de Castro (1855-1905); Archivo General de la } \\
\text { Nación, archivo del ex museo histórico nacional;Archivo de Biblioteca Nacional, sección de documentos especiales, } \\
\text { Sala Uruguay. }\end{array}$ & \\
\hline
\end{tabular}

Según este cuadro las profesiones existentes son heterogéneas y pueden catalogarse en distintos grados sociales. Destacan las ocupaciones de sastre, herrero, repartidor de diarios y artesano junto con comerciantes y militares de escala social superior. Esta es la evidencia que demuestra que la masonería uruguaya del siglo XIX no absorbía solamente a

\footnotetext{
${ }^{19}$ Martínez Esquivel, Masones y masonería, 139.
} 
miembros pudientes o exclusivamente aristocráticos sino que, por el contrario, pueden hallarse masones de extractos socio-económicos bajos y medios.

Esta es una de las características principales de la institución masónica uruguaya del siglo XIX, su carácter integrador y heterogéneo la convirtieron en un espejo de la sociedad uruguaya, no solo como aglutinadora de diferentes condiciones económicas, sino también como receptora de personas de las más distintas nacionalidades.

\section{Fuentes primarias}

Actas, cartas y diplomas del archivo privado de Carlos de Castro, Archivo General de la Nación, Montevideo.

Actas, manuales, constituciones y correspondencia de la sección de documentos especiales de sala Uruguay, Archivo de Biblioteca Nacional, Montevideo.

Documentación particular, sección masonería, Archivo del Museo Histórico Nacional, Montevideo.

Documentación particular, Archivo de la Curia, Montevideo.

\section{Bibliografía}

Breglia, Nicolás. "Revolución de Mayo y masonería". En Nueva Historia de las redes masónicas atlánticas. Coordinado por Dévrig Mollés. La Plata: Editorial de la Universidad de La Plata, 2012.

Cano Roa, Efraín. "Nacimiento y desarrollo de la masonería uruguaya en el siglo XIX”. REHMLAC+ 8, no. 2 (diciembre 2016-abril 2017): 49-69. http://dx.doi.org/10.15517/rehmlac.v7i2.22690

Del Solar Guajardo, Felipe. "La francmasonería en Chile, de sus orígenes hasta su institucionalización". REHMLAC 2, no. 1 (mayo-noviembre 2010): 1-15. https://revistas.ucr.ac.cr/index.php/rehmlac/article/view/6607/6296

Dotta Ostria, Mario. “Tres ensayos sobre la masonería en el Uruguay 1770-1870”. En Nueva Historia de las redes masónicas atlánticas. Coordinado por Devrig Molles. Argentina: Editorial de la Universidad de La Plata, 2012.

Fernández Cabrelli, Alfonso. Masones y Artiguistas en la Banda Oriental. Montevideo: s/d, 1986.

Fernández Cabrelli, Alfonso. Iglesia Ultramontana y Masonería en la transformación de la sociedad oriental. Montevideo: América Una, 1990. 
Giménez, Claudio Ariel. "Masonería y cosmopolitismo en la Argentina de finales del siglo XIX”. En Nueva Historia de las redes masónicas atlánticas. Coordinado por Dévrig Mollés. La Plata: Editorial de la Universidad de La Plata, 2012.

Larregle, Ana María. "Consideraciones sobre la masonería en la Argentina (1900-1920)". En Masonería, política y sociedad. Coordinado por José Antonio Ferrer Benimelli. Córdoba: 1987.

Martínez Esquivel, Ricardo. "Prosopografía y redes sociales: notas metodológicas sobre el estudio de la masonería en Costa Rica". REHMLAC+ 7, no. 2 (diciembre 2015-abril 2016): 1-27. https://revistas.ucr.ac.cr/index.php/rehmlac/article/view/22689/23150

Martínez Esquivel, Ricardo. Masones y masonería en la Costa Rica de los albores de la Modernidad 1865-1899. San José: Editorial de la Universidad de Costa Rica, 2017.

Mollés, Dévrig. "Nueva Historia de las redes masónicas atlánticas". En Nueva Historia de las redes masónicas atlánticas. Coordinado por Dévrig Mollés. La Plata: Editorial de la Universidad de La Plata, 2012.

Mollés, Dévrig. "Exiliados, emigrados y modernizadores. El crisol masónico euroargentino (1840-1880)". En Nueva Historia de las Redes Masónicas Atlánticas vol.1. Coordinado por Dévrig Mollés. La Plata: Editorial de la Universidad de La Plata, 2012.

Oddone, Juan Antonio. Una perspectiva europea del Uruguay. Montevideo: Universidad de la Republica, 1965.

Reyes Abadie, Washington y Andrés Vázquez Romero. Crónica General del Uruguay, tomo III. Montevideo: Banda Oriental, 1998

Salsamendi, Miguel. Crónicas del levantamiento de Columnas de las Logias nacidas bajo jurisdicción masónica uruguaya y datos biográficos de sus fundadores, desde el 21 de enero de 1830 al 30 de junio de 2000. Montevideo: Gran Logia de la Masonería del Uruguay, 2001. 